\title{
STRATEGIC MATCHING AND LINKAGE DEVELOPMENT BY AN INNOVATIVE BUSINESS SYSTEM
}

\author{
Norbert Ziemer, Northern Illinois University, nziemer@niu.edu \\ Suzanna Long, Missouri University of Science \& Technology, longsuz@mst.edu \\ Brian Mackie, Northern Illinois University, bmackie@niu.edu \\ Gerald Aase, Northern Illinois University, gaase@niu.edu \\ Deborah Gory, Northern Illinois University,dgory@niu.edu
}

\begin{abstract}
Technology based economic development and entrepreneurship is important for the growth and economic vitality of regions. Yet, the pathway to seeing these results often remains random. A procedure for economic development organizations to manage information will help businesses and entrepreneurs benefit from interactions with other businesses and entrepreneurs. It builds upon opportunity recognition theory in the entrepreneurship literature as well as resource based view and network theory streams in the strategic management literature. This research develops a procedure using a database management system, implemented by the undergraduate author in collaboration with the other authors, to identify new market and value chain opportunities using techniques that extend traditional methods used in economic development.
\end{abstract}

Keywords: Entrepreneurial Synergies, Information Capture, Visual Learning, Walk Through Audit and Business Information Systems

\section{INTRODUCTION}

It is recognized that economic development and entrepreneurial activity may help regions spur new business development and foster growth of existing businesses. However, the means for recognizing these outcomes may be demanding and often not clear-cut. Regions and their respective economic development organizations typically compete to attract new firms to their respective geographical areas. These economic development organizations have access to pools of information sources which enable them to facilitate this process. At the same time, we acknowledge the bounded rationality of organizations [11] which can apply both to the economic development organizations and to the entrepreneurs as such organizations seek to support. Strategic management research related to the resource-based view has highlighted the importance of resources, which may be further categorized as both resources (including assets) and capabilities [1]. While much of the focus of that research has been on internal use of such resources and capabilities, the present research extends these theories to leverage the value of those resources and capabilities when they are deployed into other strategic configurations. This type of deployment of resources outside their usual spheres may often be a source of profit [4].

This research showcases a framework which uses a database that can enable rapid identification of opportunities which allow two or more companies to benefit from each other's assets. This approach is designed to extend beyond and improve existing economic development approaches using industry classification information. McMullen, Plummer, \& Acs [9] assert that the nature of entrepreneurial opportunities is important to gaining better understanding of how markets come into being and function. They further argue that while there has been significant research on the discovery and exploitation of opportunities, relatively little attention has been given to the nature and source of opportunity itself. According to Vaghely and Julien [12], linking patterns of information from various sources forms the basis of innovation and new business opportunities. The system outlined in this research will make use of that very process of identifying and linking with new sources of entrepreneurial opportunities. 


\section{Issues in Information Systems}

Volume 14, Issue 2, pp.202-209, 2013

The database was developed by the undergraduate author under the guidance of the other authors. The implementation of the system began when a prototype system was created and then the undergraduate author continuously tested and revised that prototype. The system is based on a relational database model developed using Microsoft Access for both the database and the application. Beyond the system itself, the process of capturing and storing firm information is unique since the audio and video techniques capture much more of the firm's information. This gives the researchers a chance to find more of the information available about the firm which translates into a higher likelihood of identifying matches.

\section{RESEARCH}

There has been a renewed interest in entrepreneurship. Wennekers and Thurik [14] explore the association between entrepreneurship and economic growth; they cite recent econometric evidence of the significance of entrepreneurship for economic growth, employment and job creation, and international competitiveness. Economic development strategies often include efforts to attract firms to relocate to an area. Other means for spurring development may be through the building of new startup firms within communities as well as fostering innovation and expansion within established organizations. Entrepreneurship is another approach as a development strategy for replacing lost jobs and for creating new jobs [13].

\section{Collaboration, Alliances and Resource Synergies}

Eisenhardt and Schoonhoven [5] explain that two major reasons firms collaborate or form strategic alliances are strategic neeeds and social opportunities. The sharing and sourcing of resources may lead to improved strategic positioning. The strength of a firm's social position may be beneficial for strategic alliances since a strong social position helps develop competitive advantages.

Research has shown that reciprocal ties and networks of informal contacts plus access to information and know-how are crucial elements in the development of emergent technology; additionally, cross-fertilization may occur between the business incubator and industry [10]. In this research we draw many of the benefits attributed from business alliances and collaboration by gathering the same information these businesses might find because they are in close proximity and dealing with each other frequently.

One example of an interfirm synergy identified is a firm that formulates and manufactures industrial greases and lubricants connected with a biorefinery firm. They begin discussing input and output synergies to explore. The biorefinery has co-product or fractions that do not go into its primary product lines and these fractions are of very low value to the refinery firm. The lubricant firm, with its eye toward new product development and equipped with a robust chemistry laboratory, begins to explore the possibility of utilizing this biorefinery co-product as a baseline input or building block for new bio-based industrial lubricant products.

A second example is a bioscience firm which has been consulting on projects related to algae biomass. This firm is introduced to a large municipal wastewater district. The water district has noticed that algae grow naturally at its processing facility, allegedly due to the high levels of available nutrients present in the water being treated. The bioscience firm declares that algae could be deliberately grown and harvested at the water district in order to perform work. The algae will effectively "eat" the undesirable nutrients; this will help the water district remain in compliance with the tightening regulations and have a biomass product harvested with new use opportunities (e.g. bio-fertilizer).

\section{Research Proposition}




\section{Issues in Information Systems}

Volume 14, Issue 2, pp.202-209, 2013

This research explores a system that assists in matching businesses opportunities and it adds much of the information that may emerge in random fashion in a business setting, for example around the water cooler or by some other means of social interaction. In business networking settings, enterprising individuals and startup businesses have more opportunities to interact which may lead to benefit either in the short-term or long-term. Additional interaction opportunities for entrepreneurs are often facilitated by economic development and Chamber of Commerce organizations, such as meet and greet sessions, newbie introductions, and business community lunches. Each of these efforts provide platforms to learn more about other firms and possibly find benefits through resources held by the other firms; these efforts encourage exploration and possible development of ties. The authors observe characteristics of those interactions to inform this research effort.

Granovetter [4] reminds us of the powerful impact of networks on the extent and source of innovation and the diffusion of such innovation. The system in this research may help to extend the network of a firm or entrepreneur. It can be used to find obvious matches, like many commercially available business information systems do; however, it can additionally be used to help identify potential matches which are not obvious. By adding this capability, the system will have an increased likelihood of generating new, non-obvious matches. These new matches represent potential for entrepreneurs to explore new opportunities which may result in the development of businesses and overall increased economic activity. This system combines process and technology for enhanced information management with the intent of positively impacting entrepreneurial opportunity recognition. A unique process for interviewing companies has been developed in which a trained interviewer will draw out a high degree of useful information that will be used in the matching process. The interview captures a wide range of information about the firm, its present business operations, developments and challenges, as well as about areas of emerging interest for the firm's future. In addition, it also strives to find both underutilized resources and waste products that might be useful to another company

The database serves as the backend to this system and allows for storage and rapid retrieval of information. This system has the capability of not only being manually searched, but also running in an automatic mode; here, the system will search and generate matches. Whether run manually or automatically, it has the opportunity to both identify matches that conventional information systems used in economic development will and additionally, it will go beyond those capabilities and generate matches and entrepreneurial opportunities based on all the additional information in the database. This research draws upon research foundations from a number of streams of research, including literature related to knowledge management, entrepreneurship, and the resource based view in strategic management.

\section{METHODOLOGY}

Economic development search processes often rely on industry codes to facilitate rapid searching across large pools of information. The approach being outlined in this research differs from more commonly accepted conventions that use industry codes to match businesses. There is a blend of both quantitative and qualitative information being captured from interviews using audio tape, and video tape of the facility tour and transferred into the system. So, the approach utilizes both process and technology innovation.

The process is described at a high level. It begins with the economic development organization identifying companies to be contacted. Then, these firms will be asked for the opportunity to conduct a site visit and interview them. The economic development organization will request permission to capture segments of this visit by means of audio/video to increase the amount of information gathered. This will allow for a more free-flowing interview, where the interviewer will not need to be as concerned about taking notes, and can really focus more on the conversation and interaction with the firm being interviewed. The economic development organization will provide 


\section{Issues in Information Systems}

Volume 14, Issue 2, pp.202-209, 2013

assurance that the firm's information will not be disseminated to others and that this will be used to help identify new entrepreneurial opportunities.

Whenever possible, a pre-assessment will be conducted. This step will allow the company to state its needs or wants. It would be recorded to enable improved transcription when the complete interaction is later debriefed and then populated into the match profile for that particular organization. The site visit provides an opportunity for the economic development professional to learn more about the organization not only through the interview but also by touring the operation. The tour provides an opportunity to scan the operations, ask questions and take note of characteristics such as unique assets and resources. It may be that the firm has taken some of these assets for granted, and that they may be able to be leveraged for value that the firm has not yet recognized. The process, and even the video, may help to highlight "useful waste" and to recognize potential market opportunities for the redeployment of assets and resources.

The formative stages of this research included identification of the need for an interface to record and control the data gathered in the research process. Initial discussions led to the decision that collaborating with a student would be both beneficial to the project and an engaging experience for the student. The student was selected based on proven consulting and application development experience. This project, then, presented a dual benefit; it would result in a meaningful tool to facilitate the research as well as allow the student to apply and expand her skill set.

The undergraduate student met with her faculty advisor to begin the process of brainstorming the business requirements for the project. She organized the first set of specifications and reviewed them with collaborating researchers for feedback and input. Then, she incorporated the recommended modifications and worked with her faculty advisor to determine how these could be delivered. The authors took into consideration resource constraints such as funding, time and talent. They also examined this from an end user perspective based on the highly variable level of technology acumen and comfort level of the stakeholders who may be involved in the process of data collection and entry. The decision was made to proceed with Release 1 development using a relational database; Microsoft Access was chosen.

\section{Application Design}

The next phase began with defining the architecture of the database. After the researchers had a mutual consensus, the tables were developed and then the forms were designed. The researchers loaded test data and spent several days testing and modifying the design. Here, they found desired functionality that had been missed in the initial design process and only became apparent later in the process. These changes were incorporated and testing continued until the researchers were satisfied that the initial version met the revised business requirements for the overall research.

The researchers observed the process as it unfolded; this resulted in some takeaways and learning for future reference. They learned that after the design and system architecture phase, the use of actual business information is beneficial for the system development. This approach of incorporating business information allows for testing much earlier in the development cycle. Required functionality and features can be identified before the build phase has begun.

Release 1 is operational and we are starting to use it with companies and further populate the database. It is working well but the student author has agreed to move the database to Microsoft SQL Server and implement the applications in Visual Basic .NET. This will make the system more robust including multi-user access. So, the three step approach included developing the prototype, the iterative steps of continual feedback and revising the prototype with new information, and then the current stage of expanding the data and validating the system performance. 


\section{Issues in Information Systems}

Volume 14, Issue 2, pp.202-209, 2013

\section{Audio and Video Capture}

The interview at the location of the business organization will include audio recording of the conversation as well as video capture when appropriate. A digital voice recorder is used for the discussion. After the interview, the audio recording is uploaded to a server at the office. This will facilitate transcription of the conversation into a Word document that can be referenced in the future as frequently as necessary. The ability to rely on this recording will free up the interviewer to be much more engaged in the process, since he/she need not be taking notes voraciously and attempting to keep pace with what the interviewee is sharing.

As mentioned previously, a video recording will also be used whenever applicable. This will be applied to the portion of the visit when the business operation is toured. For example, a manufacturing shop will have many machines that are essential to the core business activities; additionally, there will be supporting infrastructure, hardware, supplies and other resources that may be less directly associated with the core business processes, but they are still needed for the overall business operations. The videotaping will include not only footage of those core process pieces but also everything used or stored at the location. This streaming footage will be invaluable once the interviewer returns to the office, once again alleviating some of the pressure of note taking for the interviewer plus allowing a "re-visiting" or a mental refresh to help the interviewer recall more details and/or become cognizant of new details that were not originally detected. Learning style and cognitive research supports the notion of utilizing different learning channels, including auditory and visual for enhanced learning [3]. The video capture will enhance the quality of the information that is retained from the visit to the organization and then subsequently transferred into the information system. Research in the operations management literature addresses the importance of the walk-through audit and visual inspection methods for best practices in manufacturing [6].

A wide range of potentially value-generating propositions may be identified through this approach. For example, a site visit and walk-through was made of a firm producing solvents and chemicals for industrial cleaning applications. Visual capture showed a large number of 330-gallon cube-shaped plastic containers or "totes" as they are referred to in the industry. The firm received its input materials for its production operations in these durable containers. However, it was stockpiling these containers onsite and it appeared they were not a source of value for the firm. Meanwhile, it was observed that another firm in that geographical region was a modestly sized biofuels production facility. Not being as large as an integrated refinery, this firm had smaller, more flexible supply chain options. In the end, this resulted in an entrepreneurial opportunity for a modestly sized intermediary supply chain firm. This intermediary did not have large tanker capabilities necessary to supply large refineries, but rather, this firm collected vegetable oils from food preparation operations. This firm was able to negotiate to procure the totes so that it could more efficiently collect reclaimed cooking oils and then deliver those to the biofuels facility using a medium sized delivery truck. This reduced the overall distribution footprint to help keep that process more economical.

\section{Site Visit}

At the site visit, the interviewer starts by talking with the company and expanding on the information given during the pre-site interview. Many of the company's hopes and wishes are discussed. Next the interviewer takes a tour of the facility notating both human resource and material surpluses and shortages. Waste products are identified and cost of disposal is documented. Special attention is given to the responses here as the information provided at this stage can translate into the identification of new opportunities for value creation. The audio recording and the video stream captured during this stage of the process will prove invaluable later for knowledge management.

After the site visit, the economic development professional begins to compile all of the information known about the firm to develop a composite. This includes the pre-site visit discourse, the site interview information, the audio tape, 


\section{Issues in Information Systems \\ Volume 14, Issue 2, pp.202-209, 2013}

the site visit video, and any other notes from the tour. This information is then transcribed into a list of surplus resources and resources that are desired or would be beneficial. Also recorded are any potential problems or strategic vulnerabilities which may be of concern in the future. All information will then be inputted into the company's match data profile.

The process starts with an interview onsite at the organization. It begins with a "Voice of the Customer" session [7]. Voice of the Customer is a practice currently in use by economic development organizations which helps create the opportunity for learning more about a particular organization. Cooper, Edgett, \& Kleinschmidt [2] refer to this approach as part of a process used by best-practice companies as an intentional discovery stage for new product and innovation efforts. They describe an approach of proactively capturing and handling ideas; otherwise, the reality is that often there is no action taken on ideas. Overall, the Voice of the Customer process seeks to gather information to learn more about the customer's perspectives, which may include expectations and preferences. The information gleaned from these "Voice of the Customer" interactions will serve to better inform the firm in terms of marketing, product development and strategy. For the purposes of this research, the Voice of the Customer interview is a starting point that invokes the dialogue, helps the customer to open up and share information, and then provides a platform from which to springboard to additional conversation that is less structured and really more open for the customer to articulate and provide input.

The "Voice of the Customer" interview process for economic development organizations typically utilizes a structured questionnaire with stock questions about the firm and its relationship to and satisfaction with the region (e.g. utilities, suppliers, technology providers, etc.). In addition to those, this research will add new questions such as "What specific resources would your organization want more access to?" and "What unused materials/products (e.g. waste, production scrap) does your operation have?" The interviewer will also ask the firm representative "What capabilities and/or capital does your firm have that are not being fully utilized?" and "What operational 'leftovers' or 'co-products' does your firm have?" Overall, this process will empower the interviewer to draw out rich information to expand the database with a range of information. It is believed the wide range of information that can be captured and managed will enhance the potential for discovering new opportunities through this search process, which will be tested in the future.

The questions help draw out useful information during the interview to identity gaps and opportunities for value chain development and management. As part of the site visit, the interviewer will observe opportunities to benefit the business and seek to identify possible waste products which may have value for a different company or in a different application. Here, we define "resources" broadly to include human capital, production surplus, scrap or coproducts from the operations, and hardware and assets from the physical plant. Overall, these may be assets that are underutilized or do not offer value to the organization.

Ideally, the information seeking efforts will include one or more site visits to the firm. A virtual tour conducted by the interviewer frequently will be employed, which will provide initial information about the organization's input/output needs and supplies. Interviewer preparation will include training to maximize the potential for rich information gathering, as well as to provide a consistent framework for the interview process. The process of visiting a firm can be very beneficial in a number of ways. The interviewer comes in with a fresh perspective. So, when he/she views the operation, there may be certain observations that prompt questions and discussion (e.g. "Why does the machine operator do this?" or "What happens to the leftover production materials that do not get converted in the transformation process?"). The fact that the interviewee is speaking to someone who has not heard this before and is listening intently may prompt the interviewee to share more information. This may result in a statement of problems or wishes that would benefit the organization. The interviewer will capture these through the audio recording, and this rich information may prove valuable at a later point. The opportunity to walk through the 


\section{Issues in Information Systems}

Volume 14, Issue 2, pp.202-209, 2013

business operations may provide much more information to an observant visitor. Consequently, the site visit outcomes will correspond to the interviewer's ability to draw out information from the firm.

\section{RESULTS}

This research effort is significant because it suggests a new approach to economic development and business assistance organizations. The ability to capture information and more effectively store and manage that information is essential. The manner in which the information is gathered differentiates this from other more conventional processes. Some of the conventional approaches include surveys and standard forms for firms to complete. While these can provide some utility, the authors assert that an improved method will augment current approaches and can increase the ability to identify new entrepreneurial opportunities.

The system was also developed in a unique manner. The researchers identified the initial opportunity, including how a strategic business information system coupled with a new process for gathering firm information at site visits, could assist in new business opportunity identification. The overall approach was to have as a backend an innovative information system to help generate non-obvious matches to be explored. These matches should help uncover interfirm synergies and opportunities for resource exchange and/or collaboration.

For the building of the database, an undergraduate student became directly involved as part of a project-based course. This project presented an opportunity to tackle a real problem for the development of the database system. It also afforded the student an opportunity to apply her skills and to have an experiential project to expand her experience and portfolio. So, there was a dual benefit to this research effort.

Lastly, the system works. The early development efforts show that the system will generate matches. This is important because the database will help to link those pieces of information from both the qualitative and quantitative inputs. The interview process with the video and audio capture is a benefit to capturing more information to be managed in the database. Thus, the process is complementary to the technology elements and the coupling of technology and process innovation can identify more new business opportunities.

\section{CONCLUSIONS}

The system outlined above is an innovative approach to increasing the rate of business connections with the purpose of helping to allocate or reallocate resources and assets to be deployed more effectively. As illustrated in the paper, the authors began an accelerated prototype implementation. The system is currently being improved in preparation for deployment on a larger scale, which will enable the database to be populated with information obtained from firms and entrepreneurs through the interview process.

An iterative systems development approach incorporating feedback and observations gathered in order to improve the system was used [8]. Faculty worked with a student on this research project as part of the university initiative for engaging undergraduate students in research. The student author's project focused on developing a system with multiuser capabilities and a more robust database management system using Microsoft SQL Server and Visual Basic development studio. This new system helps refine and improve the system, which generate a positive impact on economic development.

The system's effectiveness and value will be validated as it is further populated with company information. Further questions will be investigated and the system performance will be analyzed once further information is gathered 


\section{Issues in Information Systems}

Volume 14, Issue 2, pp.202-209, 2013

using the newly expanded database. Over the next few years, empirical analysis will examine metrics such as relationships between number of firms recorded in the database and the number of entrepreneurial match opportunities identified. The more information captured for a given firm, the better the overall portfolio of the firm's resources and capabilities are expected to become. This will increase the potential to identify more entrepreneurial matches.

This research work and system establishes a foundation to link information captured through the interviews and other interactions with entrepreneurs. The system has shown potential for increasing the identification of new business leads and business opportunities [12], which is an important factor for innovation and entrepreneurship.

\section{REFERENCES}

1. Makadok, R. (2001). Toward a Synthesis of the Resource-Based View and Dynamic-Capability Views of Rent Creation. Strategic Management Journal, 22, 5.

2. Cooper, R. G., Edgett, S. J., and Kleinschmidt, E.J. (2002). Optimizing the Stage-Gate Process: What BestPractice Companies Do. Research-Technology Management, 45, 5.

3. Hawk, T.F., and Shah, A.J. (2007). Using Learning Style Instruments to Enhance Student Learning. Decision Sciences Journal of Innovative Education, 5, 1.

4. Granovetter, M. (2005). The Impact of Social Structure on Economic Outcomes. Journal of Economic Perspectives, $19,1$.

5. Eisenhardt, K.M. and Schoonhoven, C.B. (1996). Resource-Based View of Strategic Alliance Formation: Strategic and Social Effects in Entrepreneurial Firms. Organization Science, 7, $2 .$.

6. Flynn, B. B., Schroeder, R. G., Flynn, E. J., Sakakibara, S., Bates, K.A. (1997). World-class manufacturing project: overview and selected results. International Journal of Operations \& Production Management 17, 7.

7. Gaskin, S.P., Griffin, A., Hauser, J.R., Katz, G.M., and Klein, R.L. (2010). Voice of the Customer. Wiley International Encyclopedia of Marketing.

8. Mackie, B.G, Ziemer, N.L., Russo, N.L., \& Mackie, W.E. (2004). Developing a Homegrown Course Management System - Community/course, Action/interaction Management System (CAMS). Journal of Cases on Information Technology, 6, 1.

9. McMullen, J. S., Plummer, L. A., and Acs, Z. J. (2007). What is an Entrepreneurial Opportunity? Small Business Economics, 28, 4.

10. Rothschild, L. \& Darr, A. (2005). Technological incubators and the social construction of innovation networks: an Israeli case study. Technovation, 25.

11. Kahneman, D. (2003). Maps of Bounded Rationality: Psychology for Behavioral Economics. The American Economic Review, 93, 5.

12. Vaghely, I.P. and Julien, P.A. (2010). Are opportunities recognized or constructed? An information perspective on entrepreneurial opportunity identification. Journal of Business Venturing, 25.

13. Walzer, N. (2007). Entrepreneurship and Local Development. Lexington Books.

14. Thurik, R. and Wennekers, S. (2004). Entrepreneurship, Small Business and Economic Growth. Journal of Small Business and Enterprise Development, 11, 1. 